\title{
Flexible sensors for an indoor air quality sensor system
}

\author{
Hanns-Erik Endres ${ }^{1}$, Klaus Rose ${ }^{2}$, Katja Scherbaum ${ }^{2}$,Robert Faul ${ }^{1}$, Waltraud Hell ${ }^{1}$, Karlheinz Bock ${ }^{1}$ \\ ${ }_{1}^{1}$ Fraunhofer EMFT, Hansastr. 27d, 80686 Munich, Germany, www.emft.fraunhofer.de \\ hanns-erik.endres@emft.fraunhofer.de \\ ${ }^{2}$ Fraunhofer ISC, Neunerplatz 2, 97082 Würzburg, Germany, www.isc.fraunhofer.de
}

\begin{abstract}
:
Indoor air quality monitoring and control at home and in cars are essential for energy saving, especially for highly sealed passive buildings and electrical driven cars. The demand driven ventilation assures the optimum compromise between a good air-quality and energy saving. This paper describes a sensor system measuring temperature, relative humidity and $\mathrm{CO}_{2}$ concentration based on resistive and impedimetric sensors [1]. A first system on polymer foil with Au-thin film resistors and interdigital capacitors $\left(\mathrm{rh}, \mathrm{CO}_{2}\right.$ ) demonstrates the proof of principle and enhances the capability of prior results with $\mathrm{CO}_{2}$ measurement [2].
\end{abstract}

Key words: indoor air quality, $\mathrm{CO}_{2}$ sensor, gas sensor, foil mems

\section{Flexible sensors and system}

The sensor system consists of a temperature sensor (meander, ca. $4 \mathrm{k} \Omega$ ) and two capacitive gas sensors (IDC, line/space $6 \mu \mathrm{m}$, capacitance ca. $10 \mathrm{pF}$ ) coated with chemical active polymer layers. All the sensors are manufactured on a $50 \mu \mathrm{m}$ thick $\mathrm{PI}$ foil substrate using a fine pitch thin film process (150 $\mathrm{nm} \mathrm{Au})$ in the EMFT cleanroom for MEMS-technology on $150 \mathrm{~mm}$ wafer handling substrate. The challenging use Pi-foil-substrate with a - compared to silicon or glass - rough surface limits the minimum line/space to $6 \mu \mathrm{m}$.

The humidity sensor is an IDC coated with a cellulose acetate butyrate layer (CAB) [3]. After solving of $C A B$ in an appropriate solvent mixture the layer was deposited with a manual spray pistol onto the surface. After striking the sensor foil the solution drops dried immediately and formed a rough layer with a large surface area.

The $\mathrm{CO}_{2}$ sensor consists of an IDC coated with a heteropolysiloxane layer (copolymerisation of 3-aminopropyle-trimethoxy -siloxane - AMO (Indicator) and propyltrimethoxysiloxane) [4]. The heating of the $\mathrm{CO}_{2}$ sensor is realized with a thin film heater (meander ca. $40 \Omega$, operating temperature ca. $65^{\circ} \mathrm{C}$ ), which is glued underneath the sensing IDC. All contacts are compatible to ZIF sockets with $1 \mathrm{~mm}$ pitch. The foil technology is compatible to future reel to reel production processes.

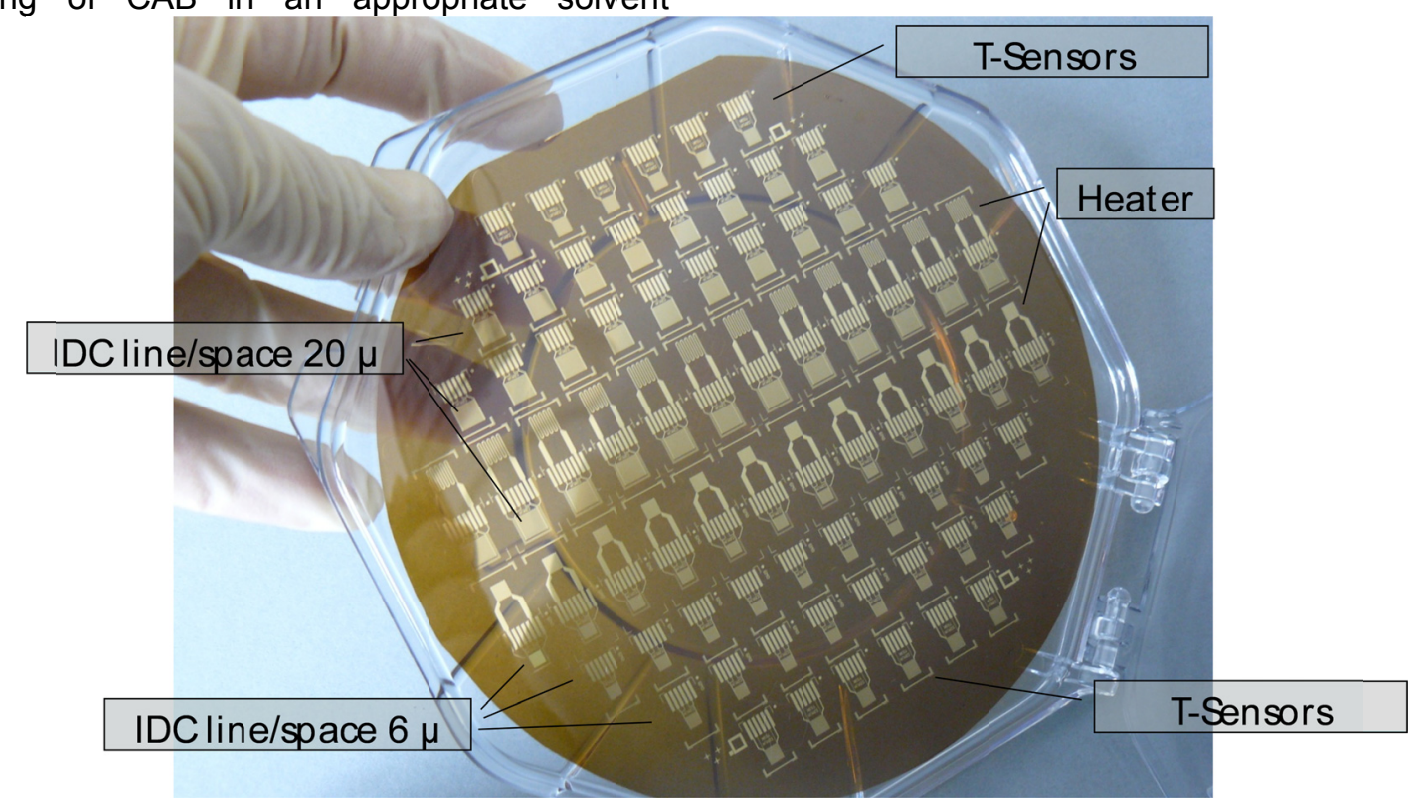

Fig. 1. Photography of the realized structures on a $200 \mathrm{~mm}$ sheet. 


\section{Experimental}

After manufacturing the sensors were tested, separated using a laser process and coated with the active layers. The test of the thin film resistors was performed on a heated chuck. The gas sensors were coated and afterwards characterized within the Fraunhofer EMFT gas measuring unit [5] whereby a specific mechanical adapter was constructed and fabricated to interface the measurement system.

\section{Results}

Characterization of the temperature sensor and the heater element is a reproducible TCR of $1630 \mathrm{ppm}$. The humidity sensors show a nearly linear humidity response within the indoor humidity range (slope 0.23 pf / $10 \%$ rh), fig. 2 .

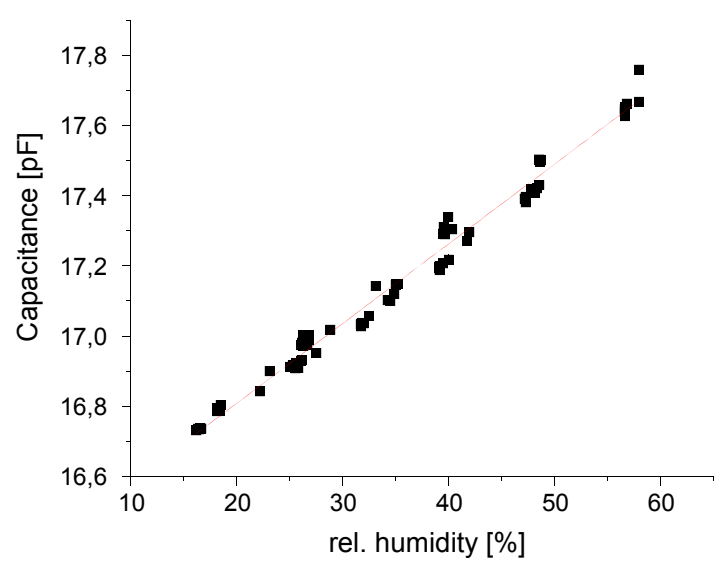

Fig. 2. Calibration curve of the humidity sensor (lin. response, no sensitivity to $\mathrm{CO}_{2}$ )

Also the $\mathrm{CO}_{2}$ sensors show a reproducible, nonlinear response to $\mathrm{CO}_{2}$ with a detection range from natural $\mathrm{CO}_{2}$ (ca. $400 \mathrm{ppm}$ ) up to

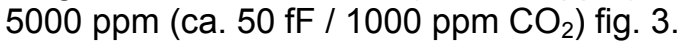

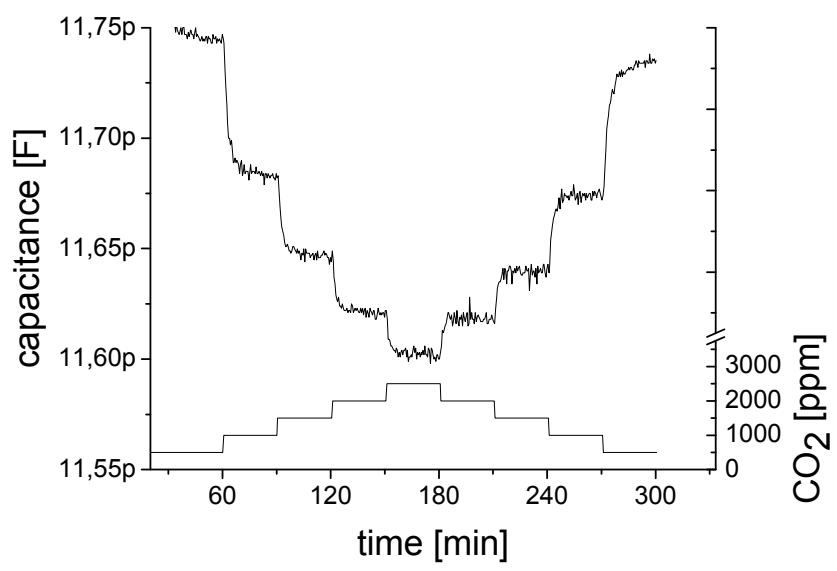

Fig. 3: Typical $\mathrm{CO}_{2}$ calibration curve $\left(T=25^{\circ} \mathrm{C}\right.$, $50 \% r h)$.
The cross sensitivity of the $\mathrm{CO} 2$ Sensor to humidity, caused by humidity adsorption of the layer and the substrate can be compensated numerically using a nonlinear formula [6].

\section{Conclusion}

The feasibility for indoor air climate sensors, based on foil substrates fabricated in the MEMS technology of Fraunhofer EMFT was investigated Several sensor characterization measurements are executed. The experiments show the possibility to develop a fully flexible indoor air quality sensor system with a minimum lifetime of 6 months. All sensors are compatible to the measuring capability of integrated circuits available on the market.

\section{Acknowledgements}

This work was financed by the European Commission within the FP7 Strep-ICTINTERFLEX GA: 247710.

\section{References}

[1] Endres, H.-E.:Air quality measurement and management. In: Gassmann, O.: Sensors in intelligent buildings Weinheim: WileyVCH, 2001, S.85-102(Sensors applications 2), DOI:10.1002/3527600302.ch2c)

[2] Oprea A. et al., Temperature, humidity and gas sensors integrated on plastic foil for low power applications, Sensors and Actuators B 140 (2009), pp 227-232, DOI:10.1016/j.snb.2009.04.019.

[3] Oprea A. et al., Capacitive humidity sensors on flexible RFID labels, Sensors and Actuators B132 (2008),pp 404-410, DOI:10.1016/j.snb.2007.10.010..

[4] Stegmeier S. et al.: Sensing mechanism of room temperature $\mathrm{CO} 2$ sensors based on primary amino groups, Sensors and Actuators B154(2011), pp. 270-276, DOI: 10.1016/j.snb.2010.01.022.

[5] Endres, H.-E. et al.: A test system for gas sensors, Sensors and Actuators. B23(1995),pp.163-172

[6] Endres, H.-E. et al.:A capacitive $\mathrm{CO}_{2}$ sensor system with suppression of the humidity interference. Sensors and Actuators. B57(1999), pp.83-87, DOI:10.1016/S0925-4005(99)00060-X) 